\title{
States, Trends, and Future of Aquaponics Research
}

\author{
Yilong Hao ${ }^{1,2}$, Kai Ding ${ }^{1, *}$, Yaoyang Xu ${ }^{1,2}$, Yuting Tang ${ }^{3} \mathbb{D}$, Dong Liu ${ }^{1,2}$ and Gang $\mathrm{Li}^{1,2, *}$ \\ 1 CAS Key Lab of Urban Environment and Health, Fujian Key Lab of Watershed Ecology, \\ Institute of Urban Environment, Chinese Academy of Sciences, Xiamen 361021, China; \\ ylhao@iue.ac.cn (Y.H.); yyxu@iue.ac.cn (Y.X.); dliu@iue.ac.cn (D.L.) \\ 2 Zhejiang Key Lab of Urban Environmental Processes and Pollution Control, \\ Ningbo Urban Environmental Observatory and Research Station, Institute of Urban Environment, \\ Chinese Academy of Science, Ningbo 315830, China \\ 3 Faculty of Science and Engineering, The School of Geographical Sciences, \\ University of Nottingham Ningbo China, Ningbo 315100, China; Yu-Ting.Tang@nottingham.edu.cn \\ * Correspondence: kding@iue.ac.cn (K.D.); gli@iue.ac.cn (G.L.)
}

Received: 1 September 2020; Accepted: 17 September 2020; Published: 21 September 2020

\begin{abstract}
As an environmentally-friendly aquaculture and planting system, aquaponics has attracted attention in various fields, such as fisheries, agriculture, and ecology. The existing review qualitatively described the development and challenges of aquaponics but lacked data support. This study selected 513 related documents (2000-2019) in the Web of Science database (WOS) to mine and quantitatively analyze its text data. The keyword co-occurrence network shows that the current aquaponics research mainly focuses on the system components, wastewater treatment, nutrient management, and system production. Research areas reflect obvious regional characteristics. China, the United States and Europe are dedicated to the application of new technologies, the optimization of system production, and the exploration of multiple roles. At present, the aquaponics development is facing many pressures from management and market. Future research requires more in-depth research in the system construction, nutrient management, and microbial community structure to provide a theoretical basis. Moreover, the identity construction within the conceptual framework of green infrastructure is a research direction worth exploring to solve low social recognition for aquaponics.
\end{abstract}

Keywords: aquaponics; text data mining; management; identity construction; green infrastructure

\section{Introduction}

In order to meet human demand for aquatic products, total global aquatic production increased by $27.5 \%$ in $2010-2018$, during which aquaculture and capture output increased by $29.8 \%$ and $10.4 \%$, respectively (FAO, 2018). Currently, capture has severely damaged species diversity [1,2], and traditional aquaculture also causes a series of problems. First, traditional aquaculture is characterized by crude management based on the natural environment [3], where weather changes and exogenous pollutants increase the risk of aquaculture disease. For instance, continuous rain will prevent the photosynthesis of phytoplankton from proceeding normally, causing water hypoxia. Secondly, the aquaculture area discharges a considerable amount of wastewater containing nitrogen, phosphorus [4], antibiotics [5], and other pollutants [6]. In addition, large-scale aquaculture of commodity fish reduces the habitat of other species [7] and disrupts the balance of the ecosystem. Therefore, it is imperative to develop a new environmentally-friendly aquaculture form.

Aquaponics is an integrated system of aquaculture and hydroponic cultivation [8]. Water circulates between the components of the system (fish tank, biofilter, hydroponic system), during which the feces of the fish become fertilizers for the plants [9], and the nitrifying bacteria in the biofilter convert the nitrogen form from ammonia to nitrate, which is absorbed by the plants [10]. The cycle of water and 
nutrients improves the efficiency of water use [11], realizes the reuse of aquaculture wastewater [12], and avoids the environmental pollution caused by traditional fisheries. Aquaponics has gotten rid of the dependence on the land and can be constructed under different scales and environmental conditions. It has attractive potential for aquaculture and urban agriculture [13].

Modern aquaponics is mainly classified according to different hydroponic form and the fact that the water cycle is closed or not. Media-Based Growing Bed (MBGB), Deep Water Culture (DWC), Nutrient Film Technique (NFT) are common forms. The three types of aquaponics have their own characteristics: MBGB is space-saving but difficult to maintain and clean. DWC is easier to clean and has a higher removal rate of nitrate, but it requires extra biofilters, aeration devices, and a larger volume of water. NFT has higher efficiency for water use but lower yield [14]. Aquaponics is divided into the coupled and decoupled system based on whether the water cycle is closed. The coupled system recycles water from the hydroponic subsystem immediately back into the aquaculture subsystem, whereas the decoupled system breaks this loop and allows water to exit the system. Compared to the coupled system, the decoupled system requires more water, but allows for better control over water quality, which leads to improved vegetable yields [15]. In addition, the size of facilities, intended objective, and applicable place also provide reference for classification.

Tilapia, ornamental fish, catfish, and leafy vegetables are the most common fish and plant species for aquaponics cultivation [16]. Hydroponic types, fish and plant density [17], flow rate, water quality parameter, feeding and planting strategies are important factors affecting yield. In addition, the distribution of nitrogen is still a critical issue that may affect the level of sustainability of an aquaponic system. Moreover, $\mathrm{pH}, \mathrm{DO}$, and hydraulic loading rate were suggested to influence the nitrogen transformation in an aquaponic system [18]. There is a difference in nitrogen utilization efficiency (NUE) and $\mathrm{N}_{2} \mathrm{O}$ emission between aquaponics with different plants [19].

There are currently 25 reviews in the Web of Science database, mainly focusing on summarizing components, types [2], economic feasibility [20], advantages and challenges of aquaponics [21]. However, quantitative analysis has not been applied to elaborate on the trend of aquaponics research. In this paper, mining the related research region, research areas, keywords and other literature text data was carried out first, and then co-occurrence analysis and cluster analysis were applied to clarify the current situation and trend of aquaponics research.

\section{Materials and Methods}

\subsection{Text Data Mining and Quantification}

The literature (2000-2019) in the WOS core database was searched with "aquaponics" as topic, related text data, such as keywords, research institute, research region, research areas, were extracted from the obtained literature. Publication indicates the popularity of keywords and research area, as well as the creativity of institutes and countries. The influence of literature, institutes, and research areas was determined through sum citations (SC), annual average citations (AC), and h index.

\subsection{Co-Occurrence Network Analysis}

Altogether, 1153 keywords and 271 research institutes were extracted from the collected publications in this study, and among which the 28 high-frequency keywords and productive institutes were selected for co-occurrence network analysis. The size of the node represents the amount of related publication of keywords or research institutes. The strength of the line represents the degree of co-occurrence between nodes, which is used to quantify the relationship between keywords or the degree of cooperation between research institutes.

\subsection{Cluster Analysis}

This study selected the six most creative countries related to aquaponics research and compared the research areas (identified by WOS database) of these countries. In order to facilitate comparison, 
the number of publications in different countries is normalized using z-score method, and cluster analysis is conducted for the research areas of these countries.

\subsection{The Publication Growth Trend Analysis}

In total, 513 publications (include articles, reviews, patents, and books) with "aquaponics" during 2000-2019 were refined from WOS database, and the annual change of publications containing high-frequency keywords with different average published time, publications of most creative countries, and common research areas were analyzed to show the growth trend of aquaponics research.

\subsection{Data Processing and Visualization}

Co-occurrence networks analysis of keywords and research institutes were performed using Vos viewer software. The analysis and visualization of the country's cooperation relationship were completed through the online analysis platform (bibliometric.com). The heat map was implemented using "pheatmap" package through R 4.0.1. Other diagrams were drawn using origin 2017.

\section{Results and Discussions}

\subsection{Current States of Aquaponics Research}

\subsubsection{Hot Issue and Research Area of Aquaponics}

The keyword co-occurrence network reflects the research hotspot of aquaponics (Figure 1). Among selected keywords, "aquaponics" has the highest frequency in publications as the center of the co-occurrence network. Followed by keywords such as "aquaculture", "hydroponic", "growth", "water", and "nitrogen" closely related to the "aquaponics". The publications of other keywords are relatively low. The overall network is radial, and the number of publications of keywords decreases with its increasing distance from the center.

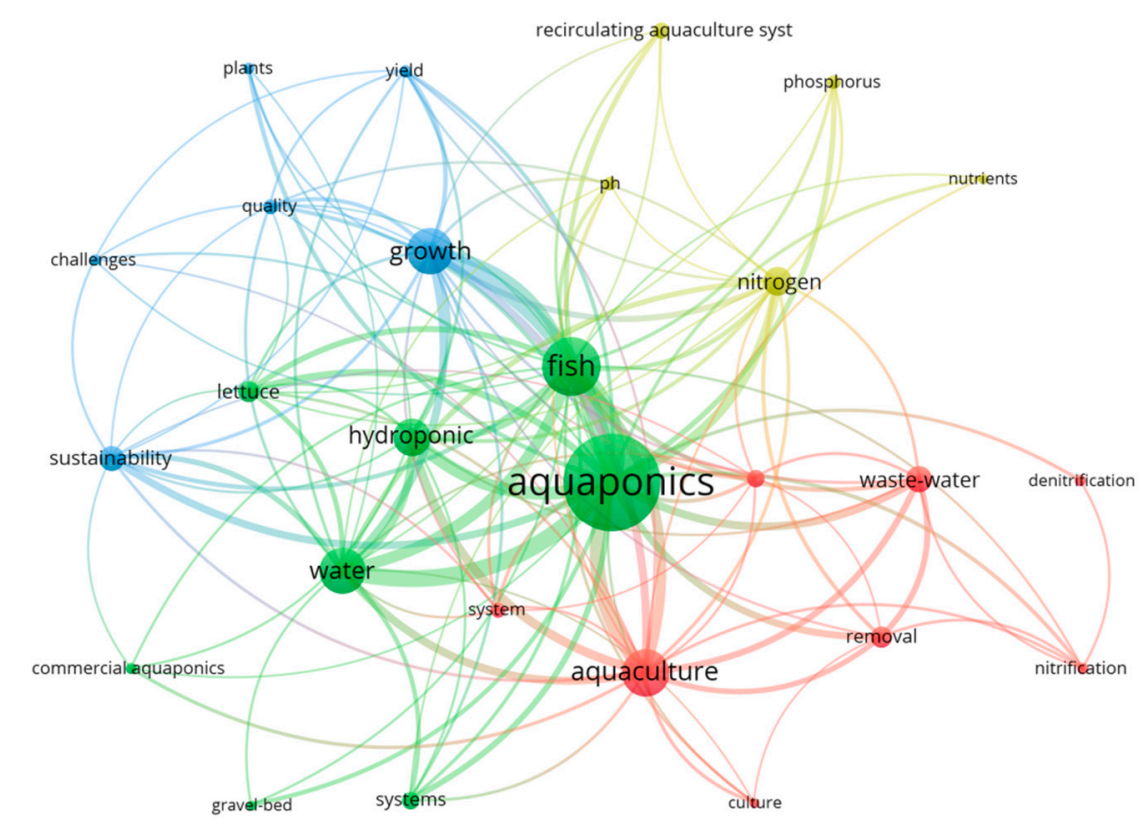

Figure 1. The co-occurrence network of high-frequency keywords.

According to the degree of association between keywords, the entire co-occurrence network is divided into four clusters with different colors. Cluster 1 (green) takes "aquaponics" as the hub, mainly focusing on the research of various parts of aquaponics (such as hydroponic). Since water is the carrier of nutrient circulation in system, hydroponic types is an important basis for distinguishing 
the aquaponics type, tilapia and lettuce are the most common fish and plants in aquaponics research, so keywords "water", "hydroponic", "Tilapia", and "lettuce" are most closely related to "aquaponics". Cluster 2 (red) takes "aquaculture" and "wastewater" as the hubs. An in-depth study was processed on the water management of aquaponics wastewater, for which "nitrification" and "denitrification" are the main regulation mechanism. Cluster 3 (yellow) mainly focuses on the study of nutrient circulation and distribution. Currently, nitrogen is the most studied nutrient element, and $\mathrm{pH}$ is the key factor affecting nutrient circulation. "growth" is the hub of cluster 4 (blue) which mainly discusses aquaponics production [22-24]. A series of requirements for system output were proposed, such as growth, yield, quality, and sustainability. In addition, compared with fish, plants are the main object of research in the cluster.

Aquaponics has attracted wide attention. Survey of the literature related to aquaponics in WOS database shows highest publications and citations in fishery- and agriculture-related research areas (MARINE FRESHWATER BIOLOGY, FISHERIES; AGRICULTURE, PLANT SCIENCES), indicating the greatest concern for aquaponics production. In addition, the hot issue of aquaponics also involved research areas including ENVIRONMENTALSCIENCES ECOLOGY, BUSINESS ECONOMICS, ENGINEERING, etc. Feasibility of aquaponics was analyzed from the perspective of environmental and market benefits, and system optimization was completed through the design of devices and the application of new technologies. As mentioned in the introduction, aquaponics can treat aquaculture wastewater and improve water use efficiency. Therefore, WATER RESOURCES is also a hot research area for aquaponics (Table 1).

Table 1. Top 10 published research areas.

\begin{tabular}{cccccc}
\hline Position & Research Area & Publication & SC & AC & h-Index \\
\hline 1 & AGRICULTURE & 379 & 2106 & 5.56 & 23 \\
2 & ENVIRONMENTAL SCIENCES ECOLOGY & 211 & 1976 & 9.76 & 20 \\
3 & MARINE FRESHWATER BIOLOGY & 183 & 2026 & 11.07 & 21 \\
4 & INSTRUMENTS INSTRUMENTATION & 180 & 358 & 1.99 & 10 \\
5 & FISHERIES & 178 & 1535 & 8.62 & 20 \\
6 & PLANT SCIENCES & 166 & 1636 & 9.86 & 21 \\
7 & ENGINEERING & 153 & 676 & 5.68 & 14 \\
8 & SCIENCE TECHNOLOGY OTHER TOPICS & 119 & 841 & 5.5 & 15 \\
9 & BUSINESS ECONOMICS & 110 & 1064 & 9.67 & 17 \\
10 & WATER RESOURCES & 97 & 987 & 10.18 & 17 \\
\hline
\end{tabular}

\subsubsection{Overview for the Research of Top 10 Influential Institutes}

Some institutes have made tremendous contributions to the research of aquaponics (Table 2). Zurich University is the most influential institute, which carried out a series of studies on the factors affecting plant growth in aquaponics. It was found that the lack of potassium inhibited the growth of plants [25], and different treatments of aquaponics wastewater also had a significant effect on the growth of plants due to different products [26]. However, the hydroponic type has no significant effect on plant growth [27]. In addition, the agency also involved the model construction of decoupled aquaponics to simulate the dynamic changes of water, nitrogen, phosphorus, sludge, fish, and plants in the system [28]. Further, the microbial diversity of each component of the system was also explored [29]. 
Table 2. Top 10 influential institutes.

\begin{tabular}{ccccc}
\hline Institutes & SC & AC & Publication & h-Index \\
\hline ZURICH UNIVERSITY OF APPLIED SCIENCES & 270 & 16.88 & 16 & 9 \\
UNIVERSITY OF HAWAII SYSTEM & 255 & 23.18 & 11 & 6 \\
UNIVERSITY OF HAWAII MANOA & 241 & 24.10 & 10 & 5 \\
STATE UNIVERSITY SYSTEM OF FLORIDA & 218 & 15.57 & 14 & 8 \\
SHANDONG UNIVERSITY & 214 & 19.45 & 11 & 7 \\
WEST VIRGINIA UNIVERSITY & 199 & 22.11 & 9 & 4 \\
UNIVERSITY OF LIEGE & 172 & 15.64 & 11 & 6 \\
HUMBOLDT UNIVERSITY OF BERLIN & 158 & 12.15 & 13 & 8 \\
LEIBNIZ INSTITUT FUR GEWASSEROKOLOGIE & 140 & 10.77 & 13 & 6 \\
UND BINNENFISCHEREI & 134 & 7.05 & 19 & 8 \\
WAGENINGEN UNIVERSITY RESEARCH & & &
\end{tabular}

Wageningen University is the most productive institute in aquaponics research. Compared with the Zurich University, Wageningen University's participation in research is more biased towards the commercialization and promotion of aquaponics. Optimization of system management was performed by constructing several models for different aquaponics type. The promotion of commercial aquaponics was performed through the system definition, market research, and economic feasibility analysis [30-34]. In addition, Shandong University and the University of Hawaii participated in a series of studies on the dynamic changes and distribution of nitrogen forms in aquaponics, and conducted an in-depth exploration of the influencing factors, such as $\mathrm{pH}$ [35], season [36], and plant species [37].

Selecting 30 high-frequency keywords from the publications of high-influence institutes for co-occurrence network analysis (Figure 2), the results show that the research of selected institutes mainly involved the growth of fish and plants (yellow), aquaculture (blue), and other related research areas (green). Similar to the previous keyword analysis result, the research on the growth of fish and plants in aquaponics includes several keywords, such as "yield", "quality", and "sustainability". For aquaculture, these institutes mainly focused on nitrogen transition and sewage treatment. In addition, these institutes also conducted research on hydroponic systems, involving keywords, such as "nitrogen", "water", and "agriculture", but showed no clear research direction.

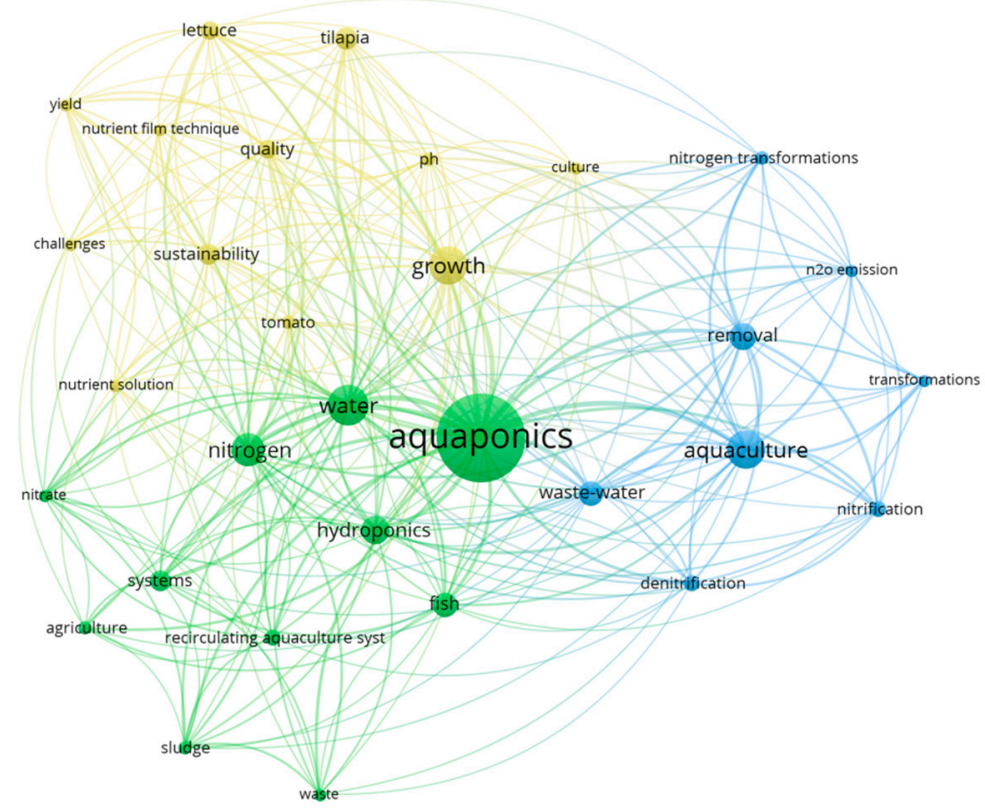

Figure 2. High-frequency keywords in abstracts of high-influence institutes publications. 
In general, the current research on aquaponics involves many fields such as fisheries, agriculture, environment, and economy. These studies mainly focused on the system itself, wastewater treatment, nutrient cycling, and crop growth. Less focus on crop growth was found in research, and the word frequency analysis also shows that the identity of aquaponics is biased toward aquaculture systems. However, "fish" and "plant" have the same word frequency. The reason for this phenomenon may be because the functions of fish and plants in the system are different. Fish in the system are mainly regarded as products or nutrients providers for plants, and plants in the system can play roles in treating farming wastewater, providing a microorganism growth environment and promoting nutrient circulation. Due to the critical role of plants in the operation of the system, the fact that plants are also system products was ignored by researchers. Even more, aquaculture management is more difficult in aquaponics operation, and hydroponic technology is basically mature. As a result, scholars prefer to regard aquaponics as an aquaculture form.

\subsubsection{Overview for the Research of Top 10 Influential Literature}

As shown in Table 3, the highly cited literature was published in 2008-2016 (the period of rapid development of aquaponics research). These reports mainly discussed the role of various factors ( $\mathrm{pH}$, plant species, etc.) and the $\mathrm{N}_{2} \mathrm{O}$ emissions during the nutrient cycle in aquaponics, which aims to improve the system production efficiency and reduce costs in order to maximize the benefits. Commercialization, sustainability, and challenges of aquaponics were also illustrated and analyzed.

Table 3. Top 10 cited literature.

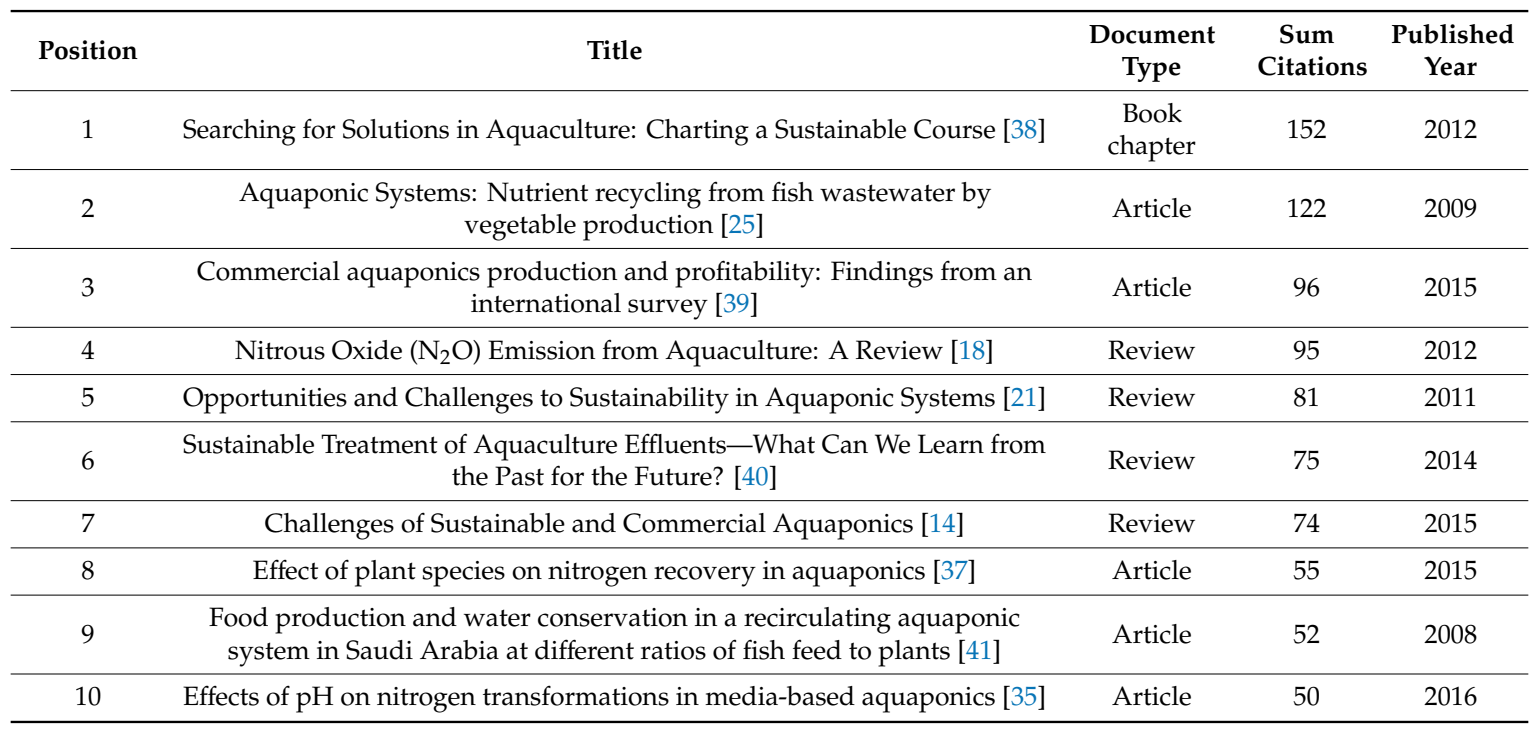

The most cited literature mainly summarized the challenges and solutions of fishery development. The survey introduced aquaponics as a new aquaculture system, compared with systems providing similar services, such as the recirculating aquaculture system (RAS). It was suggested that the existing aquaponics cannot provide the best growth conditions for fish, plants, and microorganisms at the same time, nor does it construct a model to adapt to the large-scale production [38].

Word frequency analysis was performed on the high-cited literature abstracts and 15 high-frequency keywords were selected (Table 4). Unlike the results of the co-occurrence network, high-frequency keywords involved aquaponics components, wastewater treatment, and nutrient circulation, but not growth-related research. Among them, "aquaculture" appears more frequently than "hydroponics", and "agriculture" does not appear in the selected high-frequency words, indicating that aquaponics is more frequently described as an aquaculture system than hydroponic system or agricultural system. "Fish" and "plant" appear at the same frequency, indicating that although the identity of the system is biased towards aquaculture, however, both fish and plants are important research objects for aquaponics. 
Table 4. High-frequency keywords in abstract of top 10 cited literature.

\begin{tabular}{cccc}
\hline Position & Keywords & Occurrence & Proportion \\
\hline 1 & aquaponics & 42 & $2.12 \%$ \\
2 & systems & 25 & $1.26 \%$ \\
3 & aquaculture & 24 & $1.21 \%$ \\
4 & production & 19 & $0.96 \%$ \\
5 & $\mathrm{~N}_{2} \mathrm{O}$ & 16 & $0.81 \%$ \\
6 & fish & 12 & $0.61 \%$ \\
7 & plant & 12 & $0.60 \%$ \\
8 & nitrogen & 11 & $0.56 \%$ \\
9 & wastewater & 10 & $0.50 \%$ \\
10 & emission & 9 & $0.45 \%$ \\
11 & pH & 9 & $0.45 \%$ \\
12 & water & 8 & $0.40 \%$ \\
13 & hydroponic & 8 & $0.40 \%$ \\
14 & commercial & 7 & $0.35 \%$ \\
15 & food & 7 & $0.35 \%$ \\
\hline
\end{tabular}

\subsection{The Trend of Aquaponics Research}

\subsubsection{Regional Differences of Research Direction}

Institute co-occurrence network is linear (Figure 3a), and a low-degree connection between countries was revealed (Figure 3b). The collaboration relationship reflected obvious geographic relevance, pointing that independent research and local regional cooperation are the main forms of organization for aquaponics research. The research on aquaponics carried out by relevant institutions in Europe and China was later than that in the United States.

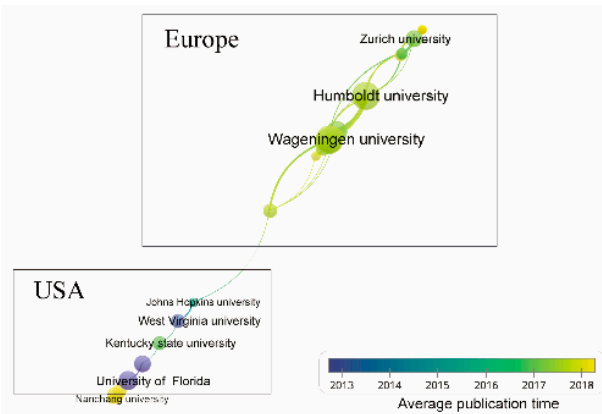

(a)
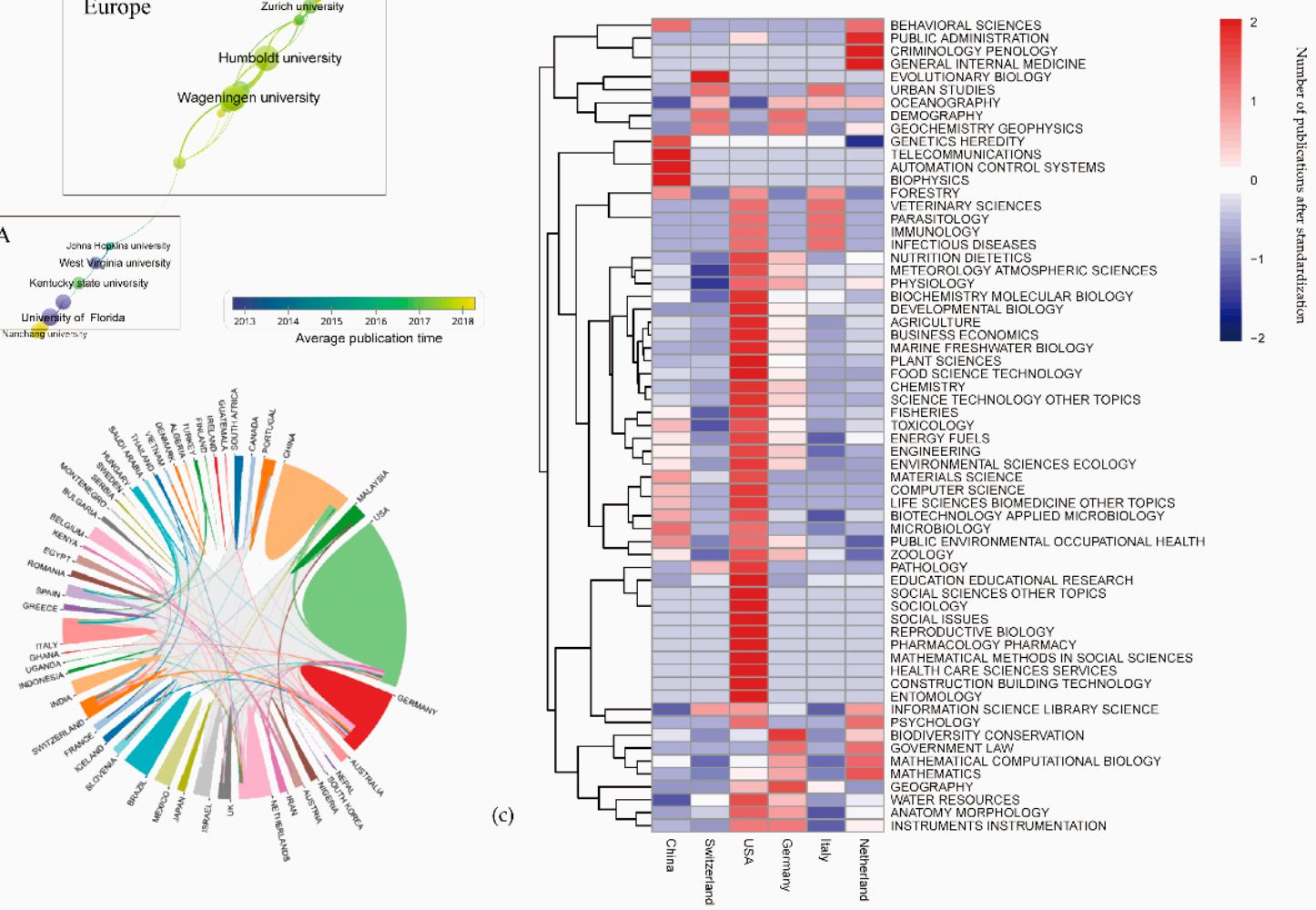

Figure 3. (a) Cooperation network of institutes. (b) Number of publications and cooperation in various countries. (The colors represent different countries) (c) Research areas of top six creative countries. 
The publications (2000-2019) of the top six creative countries in 63 related research areas were shown (Figure 3c). USA was the most creative country with research on aquaponics covers 42 research areas and had more publications than other countries in 33 research areas involving aquaponics management, disease prevention, commercialization, and promotion. Research of other countries had their own research direction of interest. For example, many studies of China focused on the application of molecular biological methods and Internet of Things (IoT) technology in aquaponics. Researchers in European countries (Netherland, Germany, Italy, Switzerland) discussed the multi-identity (Public Administration, Government Law) and the multi-function of aquaponics (URBAN STUDIES, BIODIVERSITY CONSERVATION).

Different development of aquaponics research may be due to the different attitudes towards the aquaponics system. According to surveys of relevant practitioners in USA [16] and Europe [42], compared with USA, practitioners in Europe had better educational background, the proportion of practitioners with a post-graduate degree was $91.7 \%$, which was only $24 \%$ in USA. However, the proportion of commercial production was lower, which was $19.1 \%$ in Europe and $32 \%$ in USA. In the survey, $42.6 \%$ of participating organizations in Europe were universities. Most practitioners in Europe tended to regard the aquaponic system as a studying tool, not a production tool.

\subsubsection{The Hot Issue Transition of Aquaponics Research}

The average published year of keywords indicated the development trend of aquaponics (Figure 4). Some new keywords have appeared in research related to aquaponics production and wastewater treatment. For aquaponics production, more demand for system output is emerging, such as "yield", "sustainability", and "quality". For wastewater treatment, the removal efficiency of denitrification and nitrification in aquaponics are being further studied [43]. Generally, the entire network is radial, and shows obvious transition from internal components (fish, water, nitrogen, etc) to external characteristics (yield, quality, sustainability).

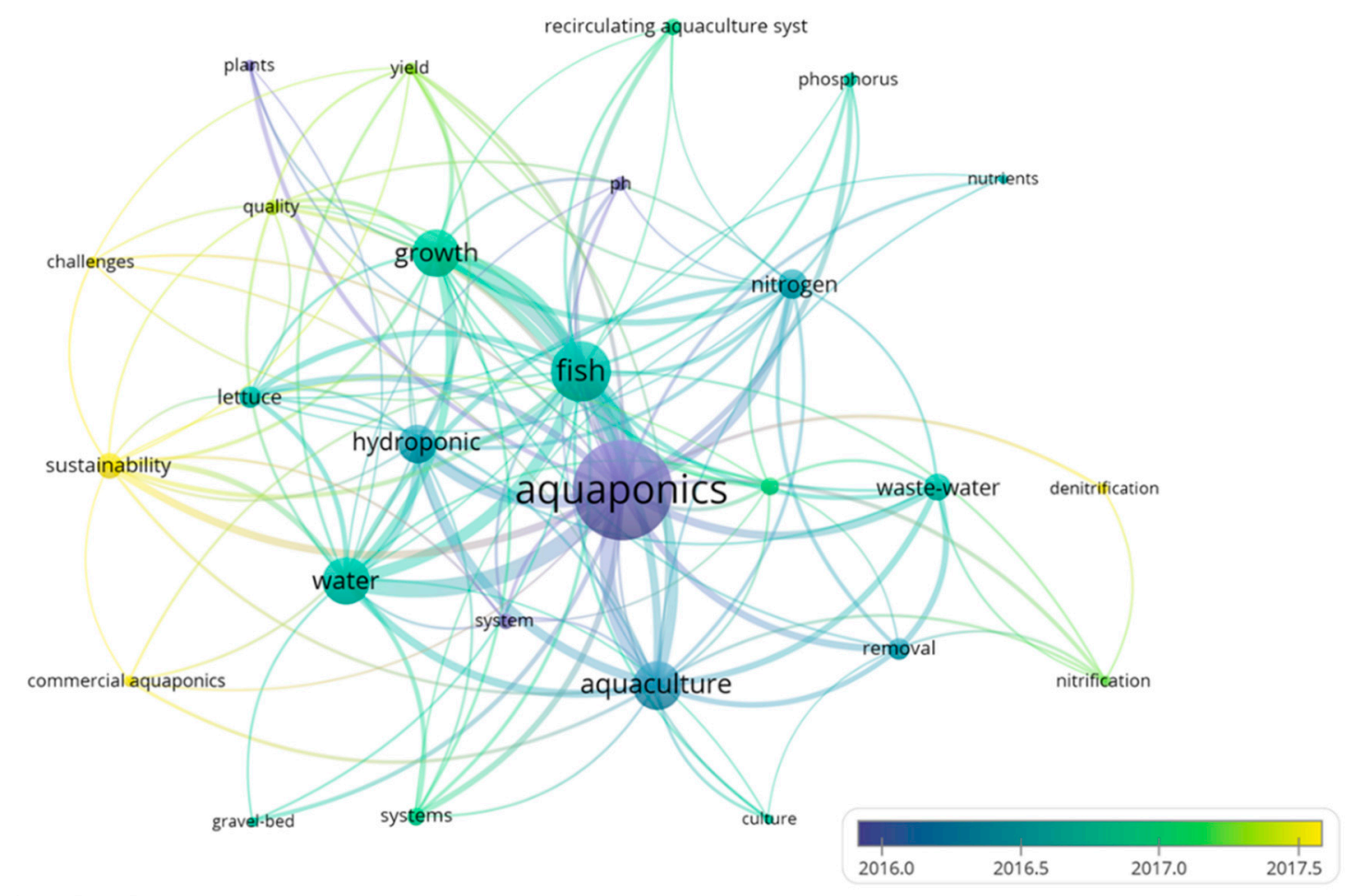

Figure 4. The average published year of high-frequency keywords. 
Besides keywords in the co-occurrence network, currently, some new topics have been suggested, such as feasibility of aquaponic system. Researchers compared the input and output of aquaponics products: the energy cost of tilapia production was twice higher than that of plants [11]. Maucieri built a micro-aquaponic system $\left(1.5 \mathrm{~m}^{2}\right)$ using recycled material and tested its feasibility through life cycle assessment (LCA) analysis [44]. Ghamkhar performed a LCA analysis for the aquaponic system in a cold climate to evaluate the impact of fish food, equipment, electricity, and heat on several environmental issues [45]. In addition to product properties, the educational function of aquaponics is also receiving increasing attention as a teaching tool for environmental science [46].

New technologies began to be applied in aquaponics. For instance, Kyaw designed a temperature sensor to control tank water temperature through an android application [47]. Wibowo monitored the TDS value in the aquaponics system through IoT technology in order to determine the feeding strategy [48].

\subsubsection{Annual Changes in Publications}

The growth trend of aquaponics research was described through annual changes in publications. There is a significant literature gap regarding aquaponic systems in terms of aquaculture and hydroponic (Figure 5a). To a certain extent, this confirms the view that the system positioning is biased towards aquaculture. Non-linear fitting and simple prediction were performed for the growth trend using the Logistic model (Levenberg-Marquardt algorithm), the fitted curve roughly matches the trend $\left(R^{2}=0.9912\right)$. The growth trend of publications was in line with the characteristics of the second stage of the sigmoid growth curve. The growth rate of aquaponics research increased sharply since 2010 and slowed down slightly after 2018.A similar situation appeared in publications with "aquaculture" and "hydroponics".

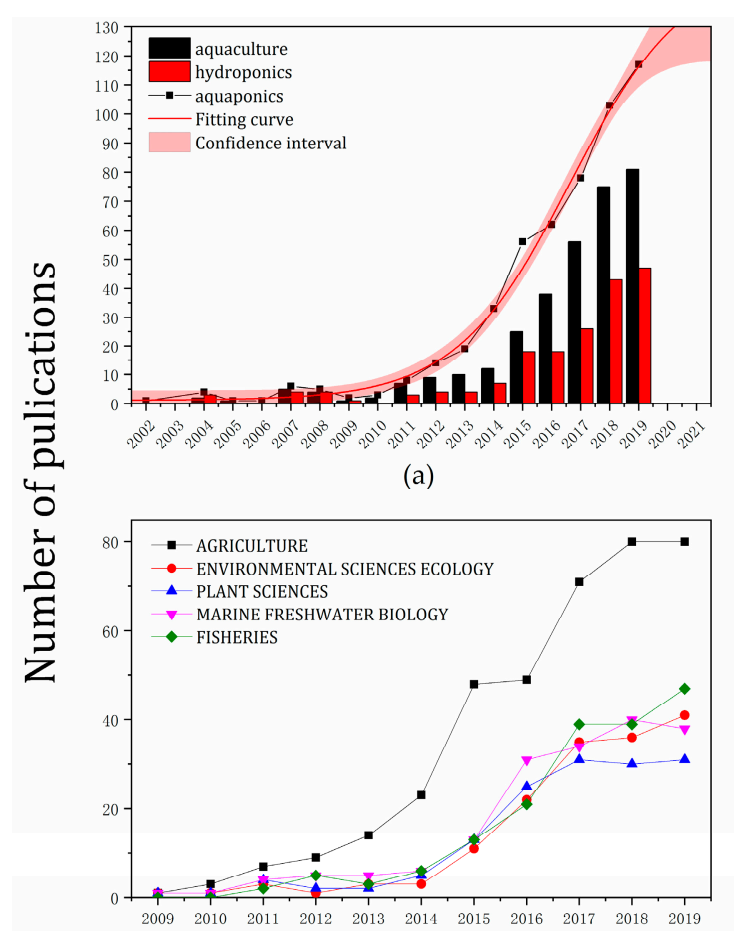

(c)

Published year

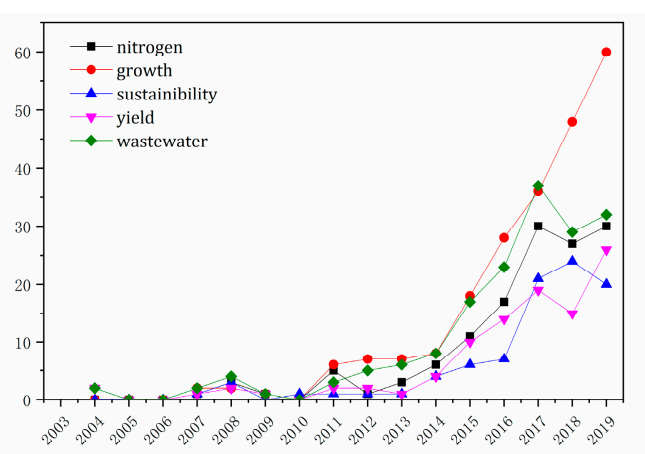

(b)

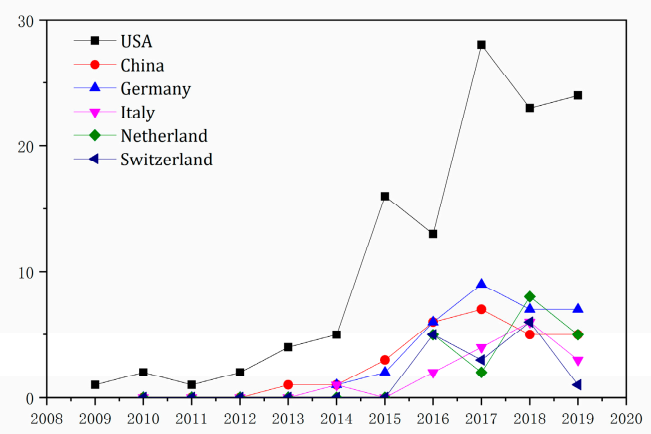

(d)

Figure 5. Annual publication growth trend of (a) aquaponics research (include aquaculture and hydroponics), (b) high-frequency keywords appearing in different times, (c) the most common research areas, (d) the most creative countries. 
The forecast of growth trend shows that the related publications will continue to grow in the future, but there is a possibility that the growth rate will decline, or even enter the third stage of the Sigmoid growth curve in the next few years. Except "growth", both the growth trend of other selected keywords related publications slowed down after 2017 (Figure 5b). A similar situation also occurs in the publication growth trend of selected countries (Figure $5 \mathrm{c}$ ) and research areas (Figure $5 \mathrm{~d}$ ). The results supported this possibility to some extent. The slowdown in the growth trend of publications indicates that the research and development of aquaponics are facing a strong challenge.

\subsection{Future of Aquaponics Research}

Several researchers summarized the challenge of aquaponics development, there are two major issues need to be solved urgently: (1) The operation and maintenance of aquaponics need more strategy [39] because insecticides and antibiotics cannot be used in aquaponics, it is difficult to prevent fish and plants from disease and pests [14]. In addition, plants have different requirements for nutrients at different growth stages [49], and it has not been resolved how to integrate the hydroponic subsystems with the aquaculture one to maximize nutrient utilization efficiency, so more culture strategies are urgently needed [23]. (2) Low social recognition: for aquaponics commercialization, high investment [34] causes high price of aquaponics products, and there is currently no policy to subsidize the initial investment in the construction of aquaponics. There are also problems, such as lack of understanding of the new method, uncertainty about its benefits, and concerns about health risks for consumers [50,51]. Without market and policy support, farmers cannot afford the cost of large-scale production, which limits the development of aquaponics.

More theoretical support is required for aquaponics culture strategy. Completed culture strategy consists of system construction and nutrient management. For system construction, the effects of influencing factors are not standardized under different aquaponics conditions (fish and plants species, hydroponics types, growth medium, etc.). Research on more effective biological methods is essential for possible risks of disease and pest. For nutrient management, the main studied element is nitrogen. Research on other elements (such as phosphorus, potassium, and sulfur) distribution in the system is needed for more comprehensive nutrient management. Current research mainly focuses on the morphological distribution and overall utilization of elements in aquaponics components. It is urgent to study the temporal dynamic changes of elements in order to coordinate fish and plants growth for finer nutrient management. In addition, microbial community drives element (such as nitrogen) circulation in aquaponics and plays a key role in nutrient management and wastewater treatment. Research on the microbial communities has been processed but far from enough $[52,53]$.

Improving market recognition needs to start with clarifying identity. As mentioned above, several studies on multi-role of aquaponics have been conducted, however, aquaponics positioning in future production and life is still unclear. As a result, related research has been involved in various disciplines, but not in-depth. There is an urgent requirement to combine the development of aquaponics with urban construction in a new conceptual framework. Green infrastructure is a type of interconnected green space network that is planned and managed for its natural resource values, and for the associated benefits, it confers to human populations [54], which has practical significance for urban planning and construction [55]. Aquaponics has functions of production, protection of biodiversity, water saving, and etc. It is a good combination of natural resources and human well-being, in line with the purpose of green infrastructure [56]. Incorporating aquaponics into the category of green infrastructure can help clarify the role in urban construction and provide the direction for aquaponics research. In addition, green infrastructure construction has been widely processed [57,58]. Identity building under the framework of green infrastructure can provide a development environment and policy support for aquaponics. 


\section{Conclusions}

At present, aquaponics research mainly focuses on the system components, wastewater treatment, nutrient management, and system production. USA, Europe, and China are the most creative regions with significantly different research directions. The aquaponics research spread from USA to Europe, research issues are expanding from internal components to external characteristics, and aquaponics identity shifted from production to multi-roles. The aquaponics development has great potential, but faces challenges of management and market. For management, more research on influencing factor, nutrient and microbial community in aquaponics are required. For market, completing the identity construction within the framework of green infrastructure provides research directions, development environment, and policy support for aquaponics. Aquaponics identity in urban production and life needs clarifying within the new conceptual framework to gain market recognition. Incorporating aquaponics into the category of green infrastructure can provide it with research directions, development environment, and policy support.

Author Contributions: Conceptualization, Y.H., G.L. and Y.X.; methodology, Y.H.; software, Y.H., D.L.; Validation: G.L., K.D., Y.X.; formal analysis, Y.H., D.L.; investigation, Y.H.; resources, G.L., Y.X.; data curation, Y.H.; writing-original draft preparation, Y.H.; writing-review and editing, Y.T., K.D., G.L., Y.X.; visualization, Y.H.; supervision, K.D., G.L., Y.X.; project administration, Y.X.; funding acquisition, Y.X. All authors have read and agreed to the published version of the manuscript.

Funding: This research was funded by Ministry of Science and Technology of China (MSTC) with National Key Research and Development Program (2017YFE0119000) and Xiamen Bureau of Science and Technology of China (3502Z20193075).

Acknowledgments: We would like to thank for Ningbo Urban Environmental Observatory and Research Station, Institute of Urban Environment, Chinese Academy of Science that has supported this research.

Conflicts of Interest: The authors declare no conflict of interest. The funders had no role in the design of the study; in the collection, analyses, or interpretation of data; in the writing of the manuscript, or in the decision to publish the results.

\section{References}

1. Worm, B.; Hilborn, R.; Baum, J.K.; Branch, T.A.; Collie, J.S.; Costello, C.; Fogarty, M.J.; Fulton, E.A.; Hutchings, J.A.; Jennings, S.; et al. Rebuilding global fisheries. Science 2009, 325, 578-585. [CrossRef] [PubMed]

2. Palm, H.W.; Knaus, U.; Appelbaum, S.; Goddek, S.; Strauch, S.M.; Vermeulen, T.; Jijakli, M.H.; Kotzen, B. Towards commercial aquaponics: A review of systems, designs, scales and nomenclature. Aquac. Int. 2018, 26, 813-842. [CrossRef]

3. Bostock, J.; McAndrew, B.; Richards, R.; Jauncey, K.; Telfer, T.; Lorenzen, K.; Little, D.; Ross, L.; Handisyde, N.; Gatward, I.; et al. Aquaculture: Global status and trends. Philos. Trans. R. Soc. B Biol. Sci. 2010, 365, 2897-2912. [CrossRef] [PubMed]

4. Troell, M.F.; Rönnbäck, P.; Halling, C.; Kautsky, N.; Buschmann, A. Ecological engineering in aquaculture: Use of seaweeds for removing nutrients from intensive mariculture. Environ. Biol. Fishes 1999, 11, 89-97. [CrossRef]

5. Hirsch, R.; Ternes, T.; Haberer, K.; Kratz, K.L. Occurrence of antibiotics in the aquatic environment. Sci. Total. Environ. 1999, 225, 109-118. [CrossRef]

6. Hites, R.A.; Foran, J.A.; Carpenter, D.O.; Hamilton, M.C.; Knuth, B.A.; Schwager, S.J. Global assessment of organic contaminants in farmed salmon. Science 2004, 303, 226-229. [CrossRef]

7. Orth, R.J.; Carruthers, T.J.B.; Dennison, W.C.; Duarte, C.M.; Fourqurean, J.W.; Heck, K.L.; Hughes, A.R.; Kendrick, G.; Kenworthy, W.J.; Olyarnik, S.; et al. A global crisis for seagrass ecosystems. Bioscience 2006, 56, 987-996. [CrossRef]

8. Rakocy, J.E. Aquaponics: The Integration of Fish and Vegetable Culture in Recirculating Systems. In Proceedings of the Caribbean Food Crops Society, 30th Annual Meeting, Virgin Islands, USA, 31 July-5 August 1994. [CrossRef]

9. Nichols, M.A.; Savidov, N.A. Aquaponics: A Nutrient and Water Efficient Production System; International Society for Horticultural Science (ISHS): Leuven, Belgium, 2012.

10. Wongkiew, S.; Hu, Z.; Chandran, K.; Lee, J.W.; Khanal, S.K. Nitrogen transformations in aquaponic systems: A review. Aquac. Eng. 2017, 76, 9-19. [CrossRef] 
11. Love, D.C.; Uhl, M.S.; Genello, L. Energy and water use of a small-scale raft aquaponics system in Baltimore, Maryland, United States. Aquac. Eng. 2015, 68, 19-27. [CrossRef]

12. Endut, A.; Jusoh, A.; Ali, N.; Nik, W.B.W. Nutrient removal from aquaculture wastewater by vegetable production in aquaponics recirculation system. Desalination Water Treat. 2011, 32, 422-430. [CrossRef]

13. Palma, L.; Dos Santos, M.J. Smart cities and urban areas-Aquaponics as innovative urban agriculture. Urban For. Urban Green. 2016, 20, 402-406.

14. Goddek, S.; Delaide, B.; Mankasingh, U.; Ragnarsdottir, K.V.; Jijakli, M.H.; Thorarinsdottir, R. Challenges of sustainable and commercial aquaponics. Sustainabilty 2015, 7, 4199-4224. [CrossRef]

15. Gibbons, G.M. An Economic Comparison of Two Leading Aquaponic Technologies Using Cost Benefit Analysis: The Coupled and Decoupled Systems. Master's Thesis, Utah State University, Logan, UT, USA, August 2020.

16. Love, D.C.; Fry, J.P.; Genello, L.; Hill, E.S.; Frederick, J.A.; Li, X.; Semmens, K. An international survey of aquaponics practitioners. PLoS ONE 2014, 9, e102662. [CrossRef] [PubMed]

17. Surnar, S.R.; Sharma, O.P.; Saini, V.P. Nutrient harvesting through aquaponics: Growth of labeo rohita and production of plant (spinach). J. Exp. Zool. India. 2017, 20, 389-396.

18. Hu, Z.; Lee, J.W.; Chandran, K.; Kim, S.; Khanal, S.K. Nitrous oxide (N2O) emission from aquaculture: A review. Environ. Sci. Technol. 2012, 46, 6470-6480. [CrossRef]

19. Wongkiew, S.; Popp, B.N.; Khanal, S.K. Nitrogen recovery and nitrous oxide (N2O) emissions from aquaponic systems: Influence of plant species and dissolved oxygen. Int. Biodeterior. Biodegrad. 2018, 134, 117-126. [CrossRef]

20. Greenfeld, A.; Becker, N.; Mcllwain, J.; Fotedar, R.; Bornman, J.F. Economically viable aquaponics? Identifying the gap between potential and current uncertainties. Rev. Aquac. 2019, 11, 848-862. [CrossRef]

21. Tyson, R.V.; Treadwell, D.D.; Simonne, E. Opportunities and challenges to sustainability in aquaponic systems. HortTechnology 2011, 21, 6-13. [CrossRef]

22. Su, M.H.; Azwar, E.; Yang, Y.; Sonne, C.; Yek, P.N.Y.; Liew, R.K.; Cheng, C.K.; Show, P.L.; Lam, S.S. Simultaneous removal of toxic ammonia and lettuce cultivation in aquaponic system using microwave pyrolysis biochar. J. Hazard. Mater. 2020, 396, 122610. [CrossRef]

23. Irhayyim, T.; Fehér, M.; Lelesz, J.; Bercsényi, M.; Bársony, P. Nutrient removal efficiency and growth of watercress (nasturtium officinale) under different harvesting regimes in integrated recirculating aquaponic systems for rearing common carp (cyprinus carpio L.). Water 2020, 12, 1419. [CrossRef]

24. Ajijah, N.; Apriyana, A.Y.; Sriwuryandari, L.; Priantoro, E.A.; Janetasari, S.A.; Pertiwi, T.Y.R.; Suciati, A.M.; Ardeniswan; Sembiring, T. Beneficiary of nitrifying bacteria for enhancing lettuce (Lactuca sativa) and vetiver grass (Chrysopogon zizanioides L.) growths align with carp (Cyprinus carpio) cultivation in an aquaponic system. Environ. Sci. Pollut. Res. 2020, 1-10. [CrossRef] [PubMed]

25. Gräber, A.; Junge, R. Aquaponic Systems: Nutrient recycling from fish wastewater by vegetable production. Desalination 2009, 246, 147-156. [CrossRef]

26. Goddek, S.; Schmautz, Z.; Scott, B.; Delaide, B.; Keesman, K.J.; Wuertz, S.; Junge-Berberovic, R. The effect of anaerobic and aerobic fish sludge supernatant on hydroponic lettuce. Agronomy 2016, 6, 37. [CrossRef]

27. Schmautz, Z.; Loeu, F.; Liebisch, F.; Graber, A.; Mathis, A.; Bulc, T.G.; Junge-Berberovic, R. Tomato productivity and quality in aquaponics: Comparison of three hydroponic methods. Water 2016, 8, 533. [CrossRef]

28. Goddek, S.; Espinal, C.A.; Delaide, B.; Jijakli, M.H.; Schmautz, Z.; Wuertz, S.; Keesman, K.J. Navigating towards decoupled aquaponic systems: A system dynamics design approach. Water 2016, 8, 303. [CrossRef]

29. Schmautz, Z.; Graber, A.; Jaenicke, S.; Goesmann, A.; Junge, R.; Smits, T.H.M. Microbial diversity in different compartments of an aquaponics system. Arch. Microbiol. 2017, 199, 613-620. [CrossRef]

30. Van Gorcum, B.; Goddek, S.; Keesman, K.J. Gaining market insights for aquaponically produced vegetables in Kenya. Aquac. Int. 2019, 27, 1231-1237. [CrossRef]

31. Palm, H.; Knaus, U.; Wasenitz, B.; Bischoff, A.; Strauch, S.M. Proportional up scaling of African catfish (Clarias gariepinus Burchell, 1822) commercial recirculating aquaculture systems disproportionally affects nutrient dynamics. Aquaculture 2018, 491, 155-168. [CrossRef]

32. Lastiri, D.R.; Geelen, C.; Cappon, H.; Rijnaarts, H.; Baganz, D.; Kloas, W.; Karimanzira, D.; Keesman, K.J. Model-based management strategy for resource efficient design and operation of an aquaponic system. Aquac. Eng. 2018, 83, 27-39. [CrossRef] 
33. Goddek, S.; Körner, O. A fully integrated simulation model of multi-loop aquaponics: A case study for system sizing in different environments. Agric. Syst. 2019, 171, 143-154. [CrossRef]

34. Bosma, R.H.; Lacambra, L.; Landstra, Y.; Perini, C.; Poulie, J.; Schwaner, M.J.; Yin, Y. The financial feasibility of producing fish and vegetables through aquaponics. Aquac. Eng. 2017, 78, 146-154. [CrossRef]

35. Zou, Y.; Hu, Z.; Zhang, J.; Xie, H.; Guimbaud, C.; Fang, Y. Effects of pH on nitrogen transformations in media-based aquaponics. Bioresour. Technol. 2016, 210, 81-87. [CrossRef] [PubMed]

36. Zou, Y.; Hu, Z.; Zhang, J.; Guimbaud, C.; Wang, Q.; Fang, Y. Effect of seasonal variation on nitrogen transformations in aquaponics of northern China. Ecol. Eng. 2016, 94, 30-36. [CrossRef]

37. Hu, Z.; Lee, J.W.; Chandran, K.; Kim, S.; Brotto, A.C.; Khanal, S.K. Effect of plant species on nitrogen recovery in aquaponics. Bioresour. Technol. 2015, 188, 92-98. [CrossRef]

38. Klinger, D.H.; Naylor, R. Searching for solutions in aquaculture: Charting a sustainable course. Annu. Rev. Environ. Resour. 2012, 37, 247-276. [CrossRef]

39. Love, D.C.; Fry, J.P.; Li, X.; Hill, E.S.; Genello, L.; Semmens, K.; Thompson, R.E. Commercial aquaponics production and profitability: Findings from an international survey. Aquaculture 2015, 435, 67-74. [CrossRef]

40. Turcios, A.E.; Papenbrock, J. Sustainable treatment of aquaculture effluents-What can we learn from the past for the future? Sustainability 2014, 6, 836-856. [CrossRef]

41. Al-Hafedh, Y.S.; Alam, A.; Beltagi, M.S. Food production and water conservation in a recirculating aquaponic system in Saudi Arabia at different ratios of fish feed to plants. J. World Aquac. Soc. 2008, 39, 510-520. [CrossRef]

42. Villarroel, M.; Junge-Berberovic, R.; Komives, T.; König, B.; Plaza, I.; Bittsanszky, A.; Joly, A. Survey of aquaponics in Europe. Water 2016, 8, 468. [CrossRef]

43. Gichana, Z.; Meulenbroek, P.; Ogello, E.O.; Drexler, S.; Zollitsch, W.; Liti, D.; Akoll, P.; Waidbacher, H. Growth and nutrient removal efficiency of sweet wormwood (artemisia annua) in a recirculating aquaculture system for Nile Tilapia (Oreochromis niloticus). Water 2019, 11, 923. [CrossRef]

44. Maucieri, C.; Forchino, A.A.; Nicoletto, C.; Junge, R.; Pastres, R.; Sambo, P.; Borin, M. Life cycle assessment of a micro aquaponic system for educational purposes built using recovered material. J. Clean. Prod. 2018, 172, 3119-3127. [CrossRef]

45. Ghamkhar, R.; Hartleb, C.; Wu, F.; Hicks, A. Life cycle assessment of a cold weather aquaponic food production system. J. Clean. Prod. 2020, 244, 118767. [CrossRef]

46. Cheng, S.C.; Hwang, G.J.; Chen, C.H. From reflective observation to active learning: A mobile experiential learning approach for environmental science education. Br. J. Educ. Technol. 2019, 50, 2251-2270. [CrossRef]

47. Kyaw, T.Y.; Ng, A.K. Smart aquaponics system for urban farming. Energy Procedia 2017, 143, 342-347. [CrossRef]

48. Wibowo, R.R.D.I.; Ramdhani, M.; Priramadhi, R.A.; Aprillia, B.S. IoT based automatic monitoring system for water nutrition on aquaponics system. J. Phys. Conf. Ser. 2019, 1367, 012071. [CrossRef]

49. Turker, H. Nutrient dynamics of different plants in an aquaponics aquaculture system. Aquat. Sci. Eng. 2018, 33, 77-83. [CrossRef]

50. Specht, K.; Zoll, F.; Schümann, H.; Bela, J.; Kachel, J.; Robischon, M. How will we eat and produce in the cities of the future? From edible insects to vertical farming-A study on the perception and acceptability of new approaches. Sustainability 2019, 11, 4315. [CrossRef]

51. Eichhorn, T.; Meixner, O. Factors influencing the willingness to pay for aquaponic products in a developed food market: A structural equation modeling approach. Sustainability 2020, 12, 3475. [CrossRef]

52. Sanchez, F.A.; Vivian-Rogers, V.R.; Urakawa, H. Tilapia recirculating aquaculture systems as a source of plant growth promoting bacteria. Aquac. Res. 2019, 50, 2054-2065. [CrossRef]

53. Oliveira, V.; Martins, P.; Marques, B.; Cleary, D.F.R.; Lillebø, A.I.; Calado, R. Aquaponics using a fish farm effluent shifts bacterial communities profile in halophytes rhizosphere and endosphere. Sci. Rep. 2020, 10, 1-11. [CrossRef]

54. Benedict, M.A.; McMahon, E.T.; Fund, M.A.T.C.; Bergen, L. Green Infrastructure: Linking Landscapes and Communities; Island Press: Washington, DC, USA, 2012.

55. Sanesi, G.; Colangelo, G.; Lafortezza, R.; Calvo, E.; Davies, C. Urban green infrastructure and urban forests: A case study of the Metropolitan Area of Milan. Landsc. Res. 2017, 42, 164-175. [CrossRef] 
56. Tzoulas, K.; Korpela, K.; Venn, S.; Yli-Pelkonen, V.; Kaźmierczak, A.; Niemelä, J.; James, P. Promoting ecosystem and human health in urban areas using Green Infrastructure: A literature review. Landsc. Urban Plan. 2007, 81, 167-178. [CrossRef]

57. Sandström, U.G. Green infrastructure planning in urban Sweden. Plan. Pract. Res. 2002, 17, $373-385$. [CrossRef]

58. Mell, I. Global Green Infrastructure: Lessons for Successful Policy-Making, Investment and Management; Routledge: New York, NY, USA, 2016.

(C) 2020 by the authors. Licensee MDPI, Basel, Switzerland. This article is an open access article distributed under the terms and conditions of the Creative Commons Attribution (CC BY) license (http://creativecommons.org/licenses/by/4.0/). 